\title{
Rendimiento en la producción de biogás a partir de la co-digestión anaeróbica de estiércol vacuno y maíz
}

Ana C. Palavecino ${ }^{1}$; Ana C. Herrera ${ }^{1}$; Sánchez de Pinto, María I. ${ }^{1}$; Sogari, Noemi ${ }^{2}$

\section{Resumen}

Se evaluó la producción de biogás a partir de estiércol vacuno y maíz luego de 57 días de co-digestión anaeróbica (DA). Se utilizaron 4 reactores plásticos de $5 \mathrm{~L}$ de capacidad diseñados con tubos para muestreo y gasómetros con mangueras y válvulas para determinar volumen y composición del biogás. En los reactores se introdujo una mezcla acuosa de estiércol vacuno fresco (sustrato), efluente activo (inóculo), maíz triturado (co-sustrato) hasta alcanzar concentraciones del $0 \%$ (Control), $1 \%, 5 \%$ y $10 \% \mathrm{~m} / \mathrm{m}$ (considerando \%ST del sustrato) hasta un volumen de $3 \mathrm{~L}$. Temperatura constante $37^{\circ} \mathrm{C}$ y agitación manual. Se midió volumen y composición del biogás diariamente, obteniéndose los volúmenes acumulados de biogás: 29L (C), 36,7L (1\%), 47,1L (5\%) y 67,9L (10\%) y de CH4: 7L (C), 14,7L
(1\%), 15,3L (5\%) y 25,7L (10\%). A mayor contenido de maíz, mayores los volúmenes de biogás y $\mathrm{CH} 4$ liberados. Se observó un aumento en los rendimientos con el agregado de maíz en relación al control, siendo el tratamiento $10 \%$ el que más favoreció la DA y la producción de biogás.

Palabras claves: biogás, co-digestión, estiércol vacuno, maíz.

\section{Abstract}

The production of biogas from cow dung and corn after 57 days of anaerobic co-digestion ( $A D$ ) was evaluated. The $A D$ was performed in 4 plastic reactors of $5 \mathrm{~L}$ capacity designed with sampling tubes and gasometers with hoses and valves to determine volume and composition of the biogas. In the reactors, a aqueous mixture of fresh cow manure (substrate), active effuent

1. Instituto de Ciencias Químicas, Facultad de Agronomía y Agroindustrias, Universidad Nacional de Santiago del Estero, 4200 Santiago del Estero, Argentina, e-mail: cecilia_palavecino_84@hotmail.com

2. Grupo de Investigación, Desarrollo y Transferencia de Energías Renovables y del Ambiente, Dpto. de Física FaCENA - UNNE. 
(inoculum), crushed maize (co-substrate) was introduced until reaching concentrations of $0 \%$ (Control), 1\%, 5\% and 10\% $w / w$ (considering \% TS of the substrate) up to a volume of $3 \mathrm{~L}$. Constant temperature at $37^{\circ} \mathrm{C}$ and manual agitation. The volume and composition of the biogas was measured daily, obtaining the accumulated volumes of biogas: $29 L(C), 36.7 L$ (1\%), $47.1 \mathrm{~L} \mathrm{(5 \% )} \mathrm{and} \mathrm{67.9L} \mathrm{(10 \% ),} \mathrm{and} \mathrm{CH4:}$ $7 \mathrm{~L}(\mathrm{C}), 14.7 \mathrm{~L}(1 \%), 15.3 \mathrm{~L}(5 \%)$ and $25.7 \mathrm{~L}(10 \%)$ respectively. The higher the maize content, the greater the volumes of biogas and $\mathrm{CH} 4$ released. An increase in yields was observed with the addition of maize in relation to the control, with the 10\% treatment being the one that favored the $D A$ and the production of biogas.

Key words: biogas, co-digestion, cow manure, maize.

\section{Introducción}

El crecimiento poblacional y la creciente demanda de alimentos han desencadenado un incremento en las actividades agro-ganaderas para suplir esa necesidad. Debido a la cría extensiva de ganado existe una importante cantidad de eyecciones residuales, cuya disposición resulta en un claro problema ambiental. Actualmente la materia orgánica $(\mathrm{MO})$ contenida en estos restos se considera una importante fuente de energía alternativa y existen varios sistemas disponibles para aprovecharla de una manera ambientalmente aceptable [1]. E1 papel de la digestión anaeróbica (DA) para el procesamiento de residuos orgánicos rurales es clave, ya que proporciona com- bustible en forma de biogás, un fertilizante fácilmente asimilable por las plantas, con altos porcentajes de $\mathrm{MO}$ y nutrientes para el desarrollo vegetal como N, P, K, Mg y $\mathrm{Ca}$ [2], y además representa un método de saneamiento que estabiliza la MO presente en los residuos tratados y reduce su volumen. La DA es entonces, una tecnología disponible para producir energía renovable, reducir las emisiones de gases de efecto invernadero (GEI), generar energía a partir de recursos renovables e incrementar la eficiencia energética a partir de diferentes sustratos de bajo costo [3].

Tradicionalmente se han utilizado distintas fuentes de desechos animales: bovinos, porcinos o avícolas como monosustratos para alimentar los biodigestores. Sin embargo, esta práctica ha sido reconocida como poco conveniente y puede no representar la forma más eficiente de producir biogás [4]. La digestión simultanea de varios residuos o co-digestión, proporciona un enfoque atractivo para mejorar la eficiencia de la biodigestión, ya que se pueden usar los nutrientes y la diversidad bacteriana presentes en estos restos para optimizar el proceso. Sus beneficios se encuentran en el equilibrio de la proporción $\mathrm{C} / \mathrm{N}$ en la mezcla de co-sustratos. Dicha relación es un indicador importante para controlar los sistemas anaeróbicos, con valores óptimos de entre 25-35. Los abonos con baja relación $\mathrm{C} / \mathrm{N}$ contienen concentraciones relativamente altas de amoníaco y probablemente inhiben la digestión anaeróbica. Esto implica que el agregado 
de cultivos con alto contenido de $\mathrm{C}$, como el maíz, podrían mejorar la relación $\mathrm{C} / \mathrm{N}$, disminuyendo así el riesgo de inhibición de la digestión por amoniaco [5].

El objetivo del trabajo fue determinar diariamente el volumen y la composición del biogás producido por co-digestión de estiércol vacuno con diferentes porcentajes agregados de maíz triturado para evaluar su calidad y rendimiento a lo largo de un periodo de 57 días de $\mathrm{DA}$ a una temperatura constante de $37^{\circ} \mathrm{C}$.

\section{Materiales y métodos}

\section{Equipo de digestión anaeróbica}

Los digestores utilizados son del tipo discontinuo de mezcla completa con crecimiento bacteriano en suspensión sin sistema de retención de biomasa. Fig. 1. Cada equipo se compone de:

- un bidón plástico de $5 \mathrm{~L}$, resistente a la deformación y a la pérdida de biogás. En la parte superior cuenta con un tubo de PVC acoplado para realizar muestreo en cualquier momento del proceso, sumergido por un lado en la mezcla y por el otro cerrado a rosca para evitar posibles pérdidas y contaminación de la mezcla. En la tapa del digestor se acopló una manguera apta para el flujo de gas, por donde se libera el biogás producido.

- un recolector de biogás por desplazamiento de agua (botella plástica graduada) con una manguera en la parte superior para conectar la sonda del equipo de medición de composición del biogás.

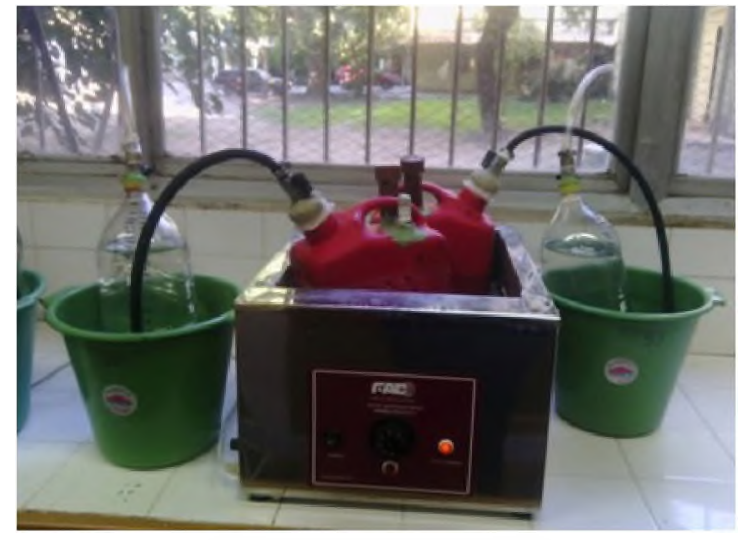

Figura 1. Equipo de DA

- un baño termostatizado para mantener constante la temperatura de trabajo en el rango mesofílico a $37^{\circ} \mathrm{C}$.

El mezclado se realiza manualmente 2 veces al día para homogenizar la mezcla, evitar la formación de sitios microbiológicamente inactivos, costras y espuma, y para ayudar a liberar el biogás generado del seno del digestor

\section{Sustrato, co-sustrato e inóculo}

Se trabaja con 3L de una mezcla acuosa de estiércol vacuno fresco (sustrato), aproximadamente al $10 \%$ de Sólidos Totales (ST), con agregado de diferentes cantidades de maíz triturado (M, co-sustrato) (1\%, $5 \%$ y $10 \% \mathrm{~m} / \mathrm{m}$ ), inoculado con efluente biológicamente activo de ensayos previos en una proporción igual al 20\% del volumen de trabajo $(0,6 \mathrm{~L})$.

\section{Métodos}

La composición del biogas $(\% \mathrm{CH} 4$, $\% \mathrm{CO} 2, \% \mathrm{O} 2$ y $\mathrm{H} 2 \mathrm{~S}$ ppm) se mide de for- 
ma directa con el equipo Biogas Analyzer Baggi modelo PGD3.

La determinación de las propiedades fisicoquímicas del estiércol vacuno, del maíz y del inoculo se realiza mediante diversas técnicas analíticas. Sólidos totales (\%ST) en estufa a $105^{\circ} \mathrm{C}$ durante 24 h. pH del extracto acuoso con $\mathrm{pH}$-metro ADWA AD1030. Sólidos volátiles (\%SV) por calcinación a $540^{\circ} \mathrm{C}$ según métodos APHA SMEWW 1999. Materia orgánica (\%MO) a partir del contenido de $\% \mathrm{SV}$ y carbono orgánico (\%COT=\%MO/1,8). Contenido de Nitrógeno total (\%NT) por Kjeldhal.

\section{Resultados}

Caracterización fisicoquímica del sustrato, co-sustrato e inóculo

En la Tabla 1 se registran los valores obtenidos de la caracterización fisicoquímica del sustrato (estiércol vacuno), $\mathrm{co}^{-}$ sustrato (maíz) y del inóculo biológicamente activo.

\begin{tabular}{c|c|c|c}
\hline \multicolumn{3}{c}{ Tabla 1. Caracterización de sustratos e inoculo } \\
\hline & Estiércol & Maíz & Inoculo \\
\hline ST $(\%)$ & 20,7 & 88,7 & 11,8 \\
SV $(\%)$ & 15,7 & 1,7 & 5,1 \\
$\mathrm{MO}(\%)$ & 75,8 & 98,3 & 43,3 \\
$\mathrm{C} / \mathrm{N}$ & 24 & 34,6 & 18,8 \\
\hline
\end{tabular}

\section{Caracterización fisicoquímica de los efluentes de entrada y salida}

La Tabla 2 contiene los datos obtenidos de la caracterización de los efluentes al inicio (E) y luego de 57 días de DA (S).

\begin{tabular}{|c|c|c|c|c|c|c|c|c|}
\hline \multirow[b]{2}{*}{ Parámetros } & \multicolumn{2}{|c|}{ C } & \multicolumn{2}{|c|}{$1 \% \mathrm{M}$} & \multicolumn{2}{|c|}{$5 \% \mathrm{M}$} & \multicolumn{2}{|c|}{$10 \% \mathrm{M}$} \\
\hline & $\mathrm{E}$ & $\mathrm{S}$ & $\mathrm{E}$ & $\mathrm{S}$ & $\mathrm{E}$ & S & $\mathrm{E}$ & S \\
\hline ST $(\%)$ & 10,8 & 8,3 & 10,4 & 8,5 & 10,4 & 8,6 & 11,9 & 8,3 \\
\hline SV $(\%)$ & 7,2 & 4,9 & 6,9 & 5,0 & 6,9 & 5,2 & 8,2 & 5,0 \\
\hline $\mathrm{pH}$ & 7,4 & 7,2 & 7,4 & 7,1 & 7,4 & 7,2 & 7,4 & 7,2 \\
\hline $\mathrm{MO}(\%)$ & 66,3 & 59,4 & 66,7 & 59,3 & 66,7 & 60,6 & 68,6 & 60,5 \\
\hline $\mathrm{C} / \mathrm{N}$ & 29,6 & 19,1 & 29,6 & 19,8 & 28,7 & 18,9 & 29,7 & 18,1 \\
\hline
\end{tabular}


El $\mathrm{pH}$ mantiene valores óptimos para la DA en todos los tratamientos y a lo largo de todo el periodo de DA. Se registró en todas las muestras reducción en los contenidos de: Sólidos totales (\%ST), Sólidos volátiles (\%SV), Materia orgánica (\%MO) y relación $\mathrm{C} / \mathrm{N}$. En todos los casos se observa una mayor disminución con el tratamiento $10 \% \mathrm{M}$.

\section{Volumen y composición del biogás gene-} rado

En la Tabla 3 se muestran la cantidad y el porcentaje de biogás liberado por cada tratamiento, a las condiciones de temperatura y mezclado establecidas.

En las Figuras 2 y 3 se ilustra la producción acumulada de biogás y $\mathrm{CH} 4 \mathrm{du}-$ rante el tiempo de DA.

Tabla 3. Volúmenes y porcentajes de biogás liberados a diferentes tiempos de DA.

\begin{tabular}{c|c|c|c|c|c|c|c|c}
\hline & \multicolumn{2}{|c|}{ Control } & \multicolumn{2}{c|}{$1 \% \mathrm{M}$} & \multicolumn{2}{c|}{$5 \% \mathrm{M}$} & \multicolumn{2}{c}{$10 \% \mathrm{M}$} \\
\hline $\begin{array}{c}\text { Días de } \\
\text { DA }\end{array}$ & Volumen & $\%$ & Volumen & $\%$ & Volumen & $\%$ & Volumen & $\%$ \\
\hline 7 & 2,35 & 8,1 & 7,00 & 19,1 & 8,10 & 17,2 & 10,90 & 16,1 \\
15 & 6,00 & 20,7 & 19,65 & 53,6 & 21,35 & 45,3 & 31,55 & 46,5 \\
30 & 15,85 & 54,6 & 26,90 & 73,4 & 32,55 & 69,1 & 48,05 & 70,8 \\
45 & 23,15 & 79,7 & 29,65 & 80,9 & 41,20 & 87,5 & 59,80 & 88,1 \\
57 & 29.05 & 100 & 36,65 & 100 & 47,10 & 100 & 67,85 & 100 \\
\hline
\end{tabular}

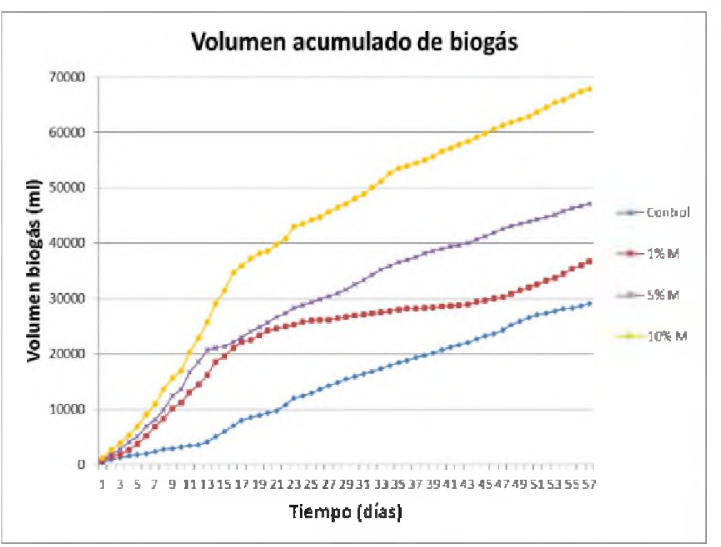

Figura 2. Volumen acumulado de biogás durante 57 días de $\mathrm{DA}$

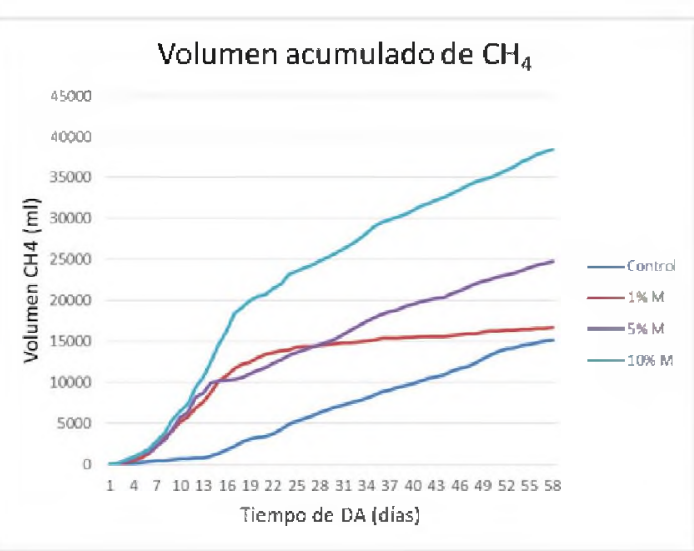

Figura 3. Volumen acumulado de $\mathrm{CH}_{4}$ durante 57 dias de DA

En la Figura 4 se observan los rendimientos de biogás y $\mathrm{CH} 4$ para los diferentes tratamientos propuestos expresados en $\mathrm{m} 3$ por $\mathrm{kg}$ de SV. 


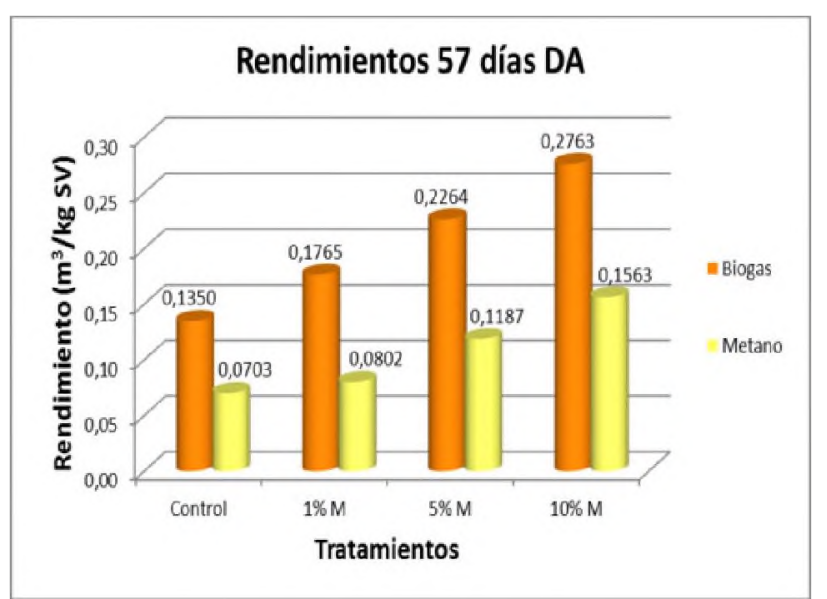

Figura 4. Rendimientos de biogás y $\mathrm{CH}_{4}$ para los diferentes tratamientos.

\section{Discusión}

Se observó que a mayor contenido de (M), mayor fue el volumen de biogás liberado: $29,05 \mathrm{~L}(\mathrm{C}), 36,65 \mathrm{~L}(1 \% \mathrm{M}), 47,10$ L (5\%M), 67,85 L (10\%M). De acuerdo a los valores de la Tabla 2, la liberación de biogás es porcentualmente mayor en los tratamientos con $\mathrm{M}$ comparados con el C, se observa una aceleración del proceso con el agregado del co-sustrato. A los 45 días de DA se liberó entre el $80 \%$ y $90 \%$ del biogás generado. Como se observa en la Fig.6, el rendimiento de biogás y de $\mathrm{CH} 4$ expresado en $\mathrm{m} 3 / \mathrm{kg}$ de $\mathrm{SV}$, aumenta progresivamente con el agregado de $\mathrm{M}$ en todas las proporciones. Según el rendimiento calculado, el contenido promedio de $\mathrm{CH} 4$ en todos los casos fue entre 45-56\% del volumen de biogás, siendo el más rico en $\mathrm{CH} 4$ el correspondiente al tratamiento $10 \% \mathrm{M}$

\section{Conclusiones}

Con el agregado gradual de maíz al $1 \%, 5 \%$, y $10 \% \mathrm{~m} / \mathrm{m}$ aumentó la producción volumétrica de biogás en relación al control. En cuanto a su composición, se ve enriquecida en $\mathrm{CH} 4$ con el agregado gradual de $\mathrm{M}$. El rendimiento del proceso de DA del estiércol vacuno como mono-sustrato puede ser optimizado con el agregado de co-sustratos ricos en C como el maíz en proporciones definidas para complementar deficiencias nutricionales del sistema. 


\section{Bibliografía}

[1] Wise, D.L., Fuel gas production of agricultural residues and municipal solid wastes by low-capital-cost batch digestión, Resources and Conservation, 13 (1987) 83-102.

[2] S. Argentino, "Sitio Argentino de Producción Animal," pp. 1-57.

[3] Campos-Montiel, R.G., O.E. del RazoRodríguez, I. Almaraz-Buendía, E. Ramírez-Bribiesca, R. Soriano-Robles, J.A. Salinas-Martínez, L. Arias-Margarito y S.S. González Muñoz, Bioconversión de desperdicios vegetales a biogás a partir de microorganismos ruminales, Rev. Int. Contam. Ambie., 34 (1), (2018) 149-155.
[4] Velásquez Piñas, J.A., O.J. Venturini, E.E. Silva Lora y O.D. Calle Roalcaba, Technical assessment of mono-digestion and co-digestion systems for the production of biogas from anaerobic digestion in Brazil, Renewable Energy 117, (2018) 447-458.

[5] Xiaojiao W., Y. Gaihe, F. Yongzhong, R. Guangxin, H. Xinhui, Optimizing feeding composition and carbon-nitrogen ratios for improved methane yield during anaerobic co-digestion of dairy, chicken manure and wheat straw, Bioresource Technology 120 (2012) 78-83. 